in vivo $35: 163-167(2021)$

doi:10.21873/invivo.12244

\title{
NR6A1 Allelic Frequencies as an Index for both Miniaturizing and Increasing Pig Body Size
}

\author{
MOE IJIRI ${ }^{1 *}$, YU-CHANG LAI ${ }^{2 *}$, HIROAKI KAWAGUCHI ${ }^{3}$, YOSHIKAZU FUJIMOTO ${ }^{1,2}$, \\ NAOKI MIURA $^{1,2}$, TOMOHIDE MATSUO $^{1,2}$ and AKIHIDE TANIMOTO 4 \\ ${ }^{1}$ Joint Faculty of Veterinary Medicine, Kagoshima University, Kagoshima, Japan; \\ ${ }^{2}$ United Graduate School of Veterinary Sciences, Yamaguchi University, Yamaguchi, Japan; \\ ${ }^{3}$ Department of Hygiene and Health Promotion Medicine, \\ Kagoshima University Graduate School of Medical and Dental Sciences, Kagoshima University, Kagoshima, Japan; \\ ${ }^{4}$ Department of Pathology, Kagoshima University Graduate School of Medical and Dental Sciences, \\ Kagoshima University, Kagoshima, Japan
}

\begin{abstract}
Background/Aim: The number of vertebrae in swine varies from 19 to 23 and is associated with body size. Nuclear receptor subfamily 6 group A member 1 (NR6A1) is considered a strong candidate for affecting the number of vertebrae in swine. Wild boars, which uniformly have 19 vertebrae, have the wild type allele while multi-vertebrae European commercial pigs have the mutated allele. Our aim was to confirm the factor of the miniaturization. Materials and Methods: We examined vertebrae number and NR6Al polymorphism in the Microminipig and three domestic breeds that vary in body size. Results: The Microminipig had 19 or less vertebrae and a wild type NR6Al genotype. Three domestic breeds had more than 21 vertebrae while the largest vertebrae number was observed in multi-vertebrae-fixed Large White. Heterozygous genotypes were observed in the middle-sized indigenous pig while homozygous NR6Al mutations were observed in European commercial breeds. Conclusion: NR6Al could be a useful index for both miniaturizing and increasing pig body size.
\end{abstract}

This article is freely accessible online.

*These Authors contributed equally to this study.

Correspondence to: Hiroaki Kawaguchi, Department of Hygiene and Health Promotion Medicine, Kagoshima University Graduate School of Medical and Dental Sciences, Kagoshima University, 8-35-1 Sakuragaoka, Kagoshima 890-8544, Japan. Tel: +81 992755291, Fax: + 81 992658434, e-mail: k3038952@kadai.jp; Akihide Tanimoto, Department of Pathology, Kagoshima University Graduate School of Medical and Dental Sciences, Kagoshima University, 8-35-1 Sakuragaoka, Kagoshima 890-8544, Japan. Tel: +81 992755263, Fax: +81992646348, e-mail: akit09@m3.kufm.kagoshima-u.ac.jp

Key Words: Minipig, domestic pig, swine, vertebrae number, NR6A1.
Pigs have been domesticated from wild boars (Sus scrofa) and various traits, including growth rate, litter, and body size have been altered through breeding. European commercial pigs have long been selectively bred for body elongation to increase meat production and improve reproductive performance (1-3). As a result of selective breeding, European commercial pigs have a few more vertebrae compared to wild boar and indigenous breeds $(3,4)$. In contrast to stockbreeding, smaller body size is expected in experimental animals.

'Amami-Shimabuta' (indigenous middle black pig breed) in the Amami-Oshima Island, located approximately $400 \mathrm{~km}$ south of mainland Kagoshima Prefecture in southwest Japan, is raised as a regional culinary specialty. The body size is smaller compared to commercial crossbreed pigs derived from Europe.

Swine are considered to be increasingly attractive toxicological and pharmacological models because of their well-accepted physiological and anatomical similarities to humans (5-10). Microminipigs (brand name; registered with the Japanese Ministry of Agriculture, Forestry and Fisheries as a novel variety of swine; Fuji Micra Inc., Shizuoka, Japan) have emerged as an experimental animal model of non-clinical pharmacological and toxicological research (1114). The body weight of a young mature Microminipig is $<10 \mathrm{~kg}$, enabling easy handling $(5,15,16)$. Some human disease models $(5,6,10,13,15,17)$ and infectious disease models (18) of Microminipig have already been developed.

Mikawa et al. (1) have suggested that a missense substitution (p.Pro192Leu) in the nuclear receptor subfamily 6 group A member 1 (NR6Al) gene, mapped to porcine chromosome 1 , is the causative mutation of a quantitative trait locus (QTL) affecting the number of vertebrae in pigs (19). Wild boars and some indigenous pig breeds have the wild type allele (C), while European commercial pigs are considered to be fixed for the mutated allele (T) (20-23). 
Table I. Information on the investigated pig breeds.

\begin{tabular}{llll}
\hline Breeds name & Use and origin & Body size* & Producing region \\
\hline Microminipig & $\begin{array}{l}\text { Experimental minipig registered with the Japanese } \\
\text { Ministry of Agriculture, Forestry and Fisheries } \\
\text { as a novel variety of swine. }\end{array}$ & Very small & Fuji Micra Inc., Shizuoka, Japan \\
Amami-Shimabuta & $\begin{array}{l}\text { culinary specialty. 'Akarinton' is one of the } \\
\text { brands used in this research. } \\
\text { Commercial breed derived from Berkshire pig, } \\
\text { branded as 'Kagoshima Kurobuta' and one of the } \\
\text { most famous pork brands in Japan. }\end{array}$ & Middle & Middle \\
Kagoshima Berkshire & $\begin{array}{l}\text { Amami-Oshima Island } \\
\text { (Approximately } 400 \text { km south-west } \\
\text { of mainland Kagoshima) } \\
\text { Various parts of Kagoshima } \\
\text { prefecture, including remote islands }\end{array}$ \\
$\begin{array}{l}\text { Multi-vertebrae-fixed } \\
\text { Large White (mv-LW) }\end{array}$ & Large & $\begin{array}{l}\text { One farm in Kagoshima mainland } \\
\text { (Southwest Japan) }\end{array}$ \\
\hline
\end{tabular}

*Classification of body size is defined by the range of general adult body weight as follows; Very small: $15-25 \mathrm{~kg}$, Middle: $200-250 \mathrm{~kg}$, Large: $300-380 \mathrm{~kg}$.

NR6Al has been studied in commercial and some indigenous pigs as well as in wild boar; however, limited studies have indicated a direct association between NR6Al polymorphism and vertebrae number (24-26). In addition, NR6Al polymorphism and vertebrae number have not been examined in Microminipigs. In the present study, we investigated vertebrae number and NR6Al gene variants in Microminipig and some domestic pig breeds of various size.

\section{Materials and Methods}

Animals. Eight Microminipigs were obtained from the breeder (Fuji Micra Inc., Shizuoka, Japan) and maintained in a dedicated room with filtered air laminar flow at Kagoshima University. Three domestic breeds: i) indigenous Amami-Shimabuta $(n=15)$, ii) Kagoshima Berkshire $(n=15)$, and iii) the multi-vertebrae-fixed Large White pig (mv-LW, $\mathrm{n}=102)$ were reared in commercial pig farms in the Kagoshima Prefecture (Table I). All protocols were approved by the Ethics Committees of Animal Care and Experimentation, Kagoshima University (MD19079). Finally, the research was performed according to the Institutional Guidelines for Animal Experiments and in compliance with the Japanese Act on Welfare and Management of Animals (Act No. 105 and Notification No. 6).

Vertebrae counting. The number of thoracic and lumbar vertebrae of Microminipigs were counted on X-ray images taken under anesthesia by an intramuscular injection of medetomidine $(0.08$ $\mathrm{mg} / \mathrm{kg})$ and midazolam $(0.08 \mathrm{mg} / \mathrm{kg})$. Three domestic breeds were examined by observation of carcass at slaughter. The rib number was counted as thoracic number. The number of analyzed animals of each breed is indicated in Table II. Thoracic and lumbar vertebrae of mv-LW pigs, except the number shown in Table II, were not distinguished because the investigation of them was done using carcass photos and the rib number could not be determined.
Table II. Vertebrae number in four pig breeds.

\begin{tabular}{lccc}
\hline Breed (number of animals) & \multicolumn{3}{c}{ Number of vertebrae } \\
\cline { 2 - 4 } & $\mathrm{TV}+\mathrm{LV}$ & $\mathrm{TV}$ & $\mathrm{LV}$ \\
\hline Microminipig (8) & $18.6 \pm 0.5^{\mathrm{a}}$ & $13.4 \pm 0.5^{\mathrm{a}}$ & $5.3 \pm 0.4^{\mathrm{a}}$ \\
Amami-Shimabuta (9) & $21.2 \pm 0.6^{\mathrm{b}}$ & $15.3 \pm 0.6^{\mathrm{bc}}$ & $5.9 \pm 0.3^{\mathrm{b}}$ \\
Kagoshima Berkshire (15) & $21.3 \pm 0.4^{\mathrm{b}}$ & $14.6 \pm 0.4^{\mathrm{b}}$ & $6.7 \pm 0.5^{\mathrm{c}}$ \\
mv-LW (7) & $22.4 \pm 0.5^{\mathrm{c}}$ & $15.7 \pm 0.5^{\mathrm{c}}$ & $6.7 \pm 0.5^{\mathrm{c}}$ \\
\hline
\end{tabular}

TV: Thoracic vertebrae; LV: lumbar vertebrae; mv-LW: multi-vertebraefixed Large White breed. Values with the different letters show the significant difference. Data are shown as mean \pm SD.

Quantitative polymerase chain reaction (qPCR) for NR6A1 genotyping. DNA was extracted from hair root samples and used for genotyping. The number of analyzed animals of each breed is indicated in Table II. The extraction was performed using the Thermo Scientific GeneJET Genomic DNA Purification Kit (Thermo Fischer Scientific, Waltham, MA, USA). Quantification and qualification of total DNA was assessed using the NanoDrop 2000c Spectrophotometer (Thermo Fisher Scientific). The custom Taqman SNP c.575T >C NR6Al missense mutation genotyping assay was designed by Thermo Fisher Scientific $(20,23)$. Quantitative PCR was performed using a TaqPath ProAmp Master Mix kit and a StepOnePlus Real-Time PCR system (Thermo Fisher Scientific). Thermal cycling was conducted according to the manufacturer's recommended program, and all experiments were performed in duplicate. In brief, $2.25 \mu \mathrm{l}$ DNA (4.5 ng in total) was added to the reaction mixtures comprised of $2.5 \mu 1$ TaqPath ProAmp Master Mix kit, $0.125 \mu \mathrm{l}$ Taqman SNP genotyping assay $(40 \mathrm{x})$ and $0.125 \mu \mathrm{l}$ Nuclease free water. The quantitative PCR was performed under the genotyping experiments fast cycling conditions: i) pre-read step at $60^{\circ} \mathrm{C}$ for $30 \mathrm{~s}$, ii) initial denaturation/enzyme activation step at $95^{\circ} \mathrm{C}$ for $5 \mathrm{~min}$, iii) 40 cycles of denaturation step at $95^{\circ} \mathrm{C}$ for $5 \mathrm{~s}$ and annealing/extension step at $60^{\circ} \mathrm{C}$ for $30 \mathrm{~s}$, and iv) pre-read step at $60^{\circ} \mathrm{C}$ for $30 \mathrm{~s}$. 
Breed

(Number of animals)

Vertebral number of pig: $\square 18 \quad \square 19 \quad \square 20 \quad \square 21 \quad \square 22 \square 23$

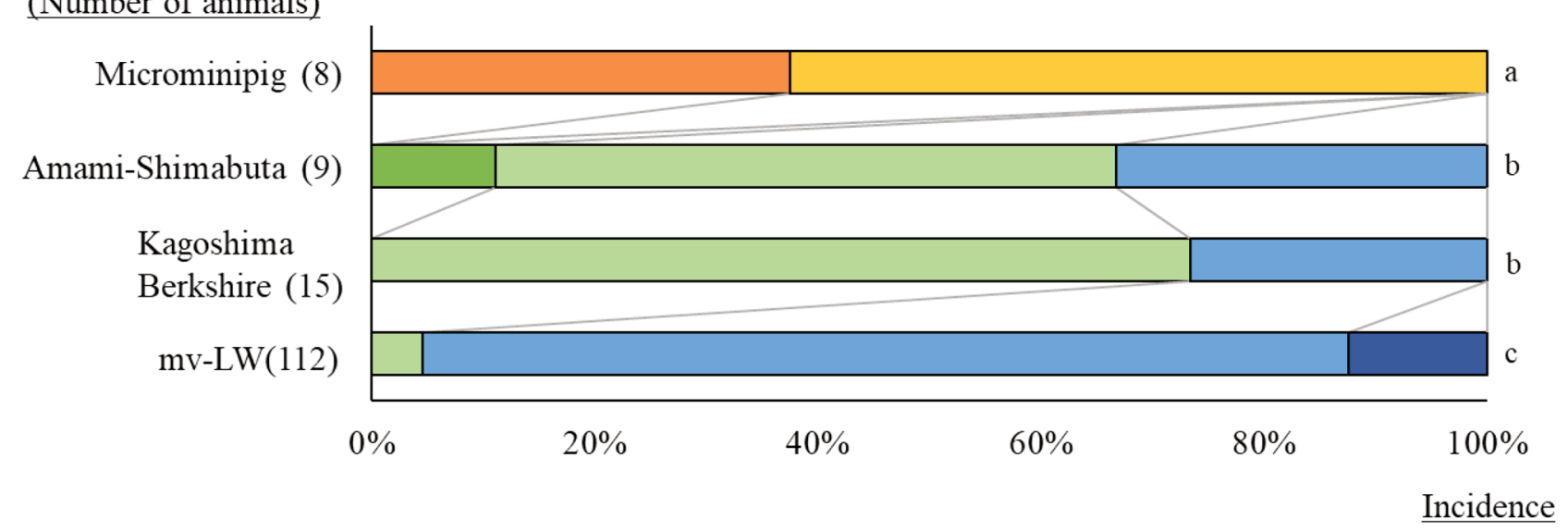

Figure 1. Pattern of vertebrae number distribution in four pig breeds. a-c: Show the distribution ratio, where different letters indicate significant differences $(p<0.01)$. mv-LW: Multi-vertebrae-fixed Large White breed.

Table III. Genotype and allele frequencies at the c.575T>C locus of NR6A1 in four pig breeds.

\begin{tabular}{lccccc}
\hline Breed (number of animals) & \multicolumn{3}{c}{ Genotype frequency } & & Allele frequency \\
\cline { 2 - 5 } & $\mathrm{TT}$ & $\mathrm{TC}$ & $\mathrm{CC}$ & $\mathrm{T}$ & $\mathrm{C}$ \\
\hline Microminipig (8) & 0.000 & 0.000 & 1.000 & 0.000 & 0.833 \\
Amami-Shimabuta (9) & 0.667 & 0.333 & 0.000 & 1.000 & 0.167 \\
Kagoshima Berkshire (15) & 1.000 & 0.000 & 0.000 & 1.000 & 0.000 \\
mv-LW (34) & 1.000 & 0.000 & 0.000 & 000 \\
\hline
\end{tabular}

mv-LW: Multi-vertebrae-fixed Large White breed.

Statistical analysis. The number of vertebrae is expressed as mean \pm standard deviation. Statistical analysis of the differences between breeds was assessed by one-way ANOVA analysis of variance, followed by the Tukey-Kramer multiple comparison test and Fisher's exact test. All statistical analyses were performed using the IBM SPSS Statistics 25 software (IBM, Tokyo, Japan), and $p<0.05$ was considered statistically significant.

\section{Results}

Vertebrae number. The Microminipig had the lowest vertebrae number while mv-LW had the highest vertebrae number (Table II). The vertebrae numbers of the two middlesized breeds were intermediate between those of the Microminipig and the mv-LW. The pattern of vertebrae number distribution of Microminipig significantly differed from the other three breeds and all Microminipigs had 19 or fewer vertebrae (Figure 1).
NR6Al genotype and allele frequencies. Homozygous $\mathrm{C} / \mathrm{C}$ genotypes were observed in Microminipigs, while homozygous $\mathrm{T} / \mathrm{T}$ genotypes were observed in mv-LW and Kagoshima Berkshire pigs (Table III). Both homozygous T/T $(n=6)$ and heterozygous $\mathrm{C} / \mathrm{T}$ genotypes $(n=3)$ were observed in AmamiShimabuta pigs. The vertebrae numbers in Amami-Shimabuta pigs with homozygous $\mathrm{T} / \mathrm{T}$ and heterozygous $\mathrm{C} / \mathrm{T}$ genotypes were $21.0 \pm 1.0$ and $21.3 \pm 0.5$, respectively, and the difference was not significant.

\section{Discussion}

The NR6Al gene, encoding an orphan nuclear receptor, is located in a $300-\mathrm{kb}$ region that is fixed in a variety of European commercial breeds (Landrace, LW, Yorkshire, Duroc, and Berkshire) (1). This gene has been focused on as a means of controlling economically important traits in the 
swine market or as a tool to discriminate between wild boar and domestic pigs $(19,27,28)$.

We found that the Microminipig was homozygous for the NR6Al C/C genotype, with a vertebrae number of lower than the 19 vertebrae uniformly found in wild boar $(3,23)$. The Microminipig is the smallest experimental minipig and represents a successful pig miniaturization. Our results indicate that the NR6Al C/C genotype could be an index of pig miniaturization. Other factors influencing decreased vertebrae numbers remain to be investigated further. To the best of our knowledge, this is first report associating NR6Al and vertebrae number in an experimental minipig.

In previous studies, the $\mathrm{C}$ allele of NR6Al has appeared in wild boars and in several indigenous pigs, especially Asian pigs $(20,22,29)$. The $\mathrm{T}$ allele frequency in AmamiShimabuta pig was higher compared to other indigenous Asian pigs $(23,29)$. This indicates that the domestication of Amami-Shimabuta is considered to be more advanced than that of the other indigenous Asian pigs examined on the body elongation to increase meat production.

In this study, the homozygous T/T genotype was observed in mv-LW pigs, as has been observed in commercial LW, Landrace, Duroc and other Western breeds (22, 23, 29). Most of the current commercial-crossbred pigs have 21 vertebrae (26), while most commercial LW pigs have 22 vertebrae, and $2.9 \%$ of them have 23 vertebrae (4). Our results show that $12.5 \%$ of mv-LW pigs have 23 vertebrae, indicating that multivertebrae traits have been successfully selected in mv-LW. Similarly, the Kagoshima Berkshire pigs were also homozygous for the T/T genotype, but the vertebrae number in this breed was lower than 22. Therefore, there are additional factors increasing vertebrae number that remain to be explored.

In conclusion, NR6A1 polymorphism could be a useful index for both miniaturizing and increasing pig body size.

\section{Conflicts of Interest}

The Authors declare no conflicts of interest.

\section{Authors' Contributions}

MI and HK collected sample material. NM designed the primer/probe system targeting the NR6Al. MI, HK, NM and AT planned the study; YCL and MI performed the experiments and analyzed the data; MI, HK and AT drafted the manuscript; YF and TM revised the draft. All Authors read and approved the final manuscript.

\section{Acknowledgements}

The Authors thank Ms. Akari Maeda for raising Kagoshima Berkshire and 'Akarinton', Mr. Akihiro Nakashima for construction of Meiko22, the Meat Hygiene Inspection Center of Kagoshima city for carcass research, and Kowadaya Co., Ltd. They are also grateful to Ms. Maiko Kawaguchi and Ms. Shiho Suzuki for their technical assistance. This work was partly supported by grants from the supporting for interdisciplinary projects in Kagoshima University (MI, HK) and Gap Fund program of General Incorporated Foundation Kyushu Open Innovation Center (HK).

\section{References}

1 Mikawa S, Morozumi T, Shimanuki S, Hayashi T, Uenishi H, Domukai M, Okumura N and Awata T: Fine mapping of a swine quantitative trait locus for number of vertebrae and analysis of an orphan nuclear receptor, germ cell nuclear factor (NR6A1). Genome Res 17(5): 586-593, 2007. PMID: 17416745. DOI: 10.1101/gr.6085507

2 Mikawa S, Hayashi T, Nii M, Shimanuki S, Morozumi T and Awata T: Two quantitative trait loci on Sus scrofa chromosomes 1 and 7 affecting the number of vertebrae. J Anim Sci 83(10): 22472254, 2005. PMID: 16160033. DOI: 10.2527/2005.83102247x

3 King JWB and Roberts RC: Carcass length in the bacon pig; its association with vertebrae numbers and prediction from radiographs of the young pig. Anim Prod 2(1): 59-65, 1960. DOI: $10.1017 /$ S0003356100033493

4 Borchers N, Reinsch N and Kalm E: The number of ribs and vertebrae in a Piétrain cross: variation, heritability and effects on performance traits. J Anim Breed Genet 121: 392-403, 2004. DOI: 10.1111/j.1439-0388.2004.00482.x

5 Kawaguchi H, Miyoshi N, Miura N, Fujiki M, Horiuchi M, Izumi $Y$, Miyajima $H$, Nagata $R$, Misumi $K$, Takeuchi T, Tanimoto A and Yoshida H: Microminipig, a non-rodent experimental animal optimized for life science research: Novel atherosclerosis model induced by high fat and cholesterol diet. J Pharmacol Sci 115(2): 115-121, 2011. PMID: 21258170. DOI: 10.1254/jphs.10R17FM

6 Kawaguchi H, Yamada T, Miura N, Ayaori M, Uto-Kondo H, Ikegawa M, Noguchi M, Wang KY, Izumi $\mathrm{H}$ and Tanimoto A: Rapid Development of Atherosclerosis in the World's Smallest Microminipig fed a high-fat/high cholesterol diet: A Useful Animal Model Because of its Size and Similarity to Human Pathophysiology. J Atheroscler Thromb 21(3): 186-203, 2014. PMID: 24257467. DOI: $10.5551 /$ jat.21246

7 Takeishi K, Kawaguchi H, Akioka K, Noguchi M, Arimura E, Abe M, Ushikai M, Okita S, Tanimoto A and Horiuchi M: Effects of dietary and lighting conditions on diurnal locomotor activity and body temperature in microminipigs. In Vivo 32(1): 55-62, 2018. PMID: 29275299. DOI: 10.21873/invivo.11204

8 Kawaguchi H, Yamada T, Miura N, Takahashi Y, Yoshikawa T, Izumi H, Kawarasaki T, Miyoshi N and Tanimoto A: Reference values of hematological and biochemical parameters for the world smallest Microminipigs. J Vet Med Sci 74(7): 933-936, 2012. PMID: 22362255. DOI: 10.1292/jvms.11-0571

9 Miura N, Kawaguchi H, Nagasato T, Yamada T, Ito T, Izumi H, Shameshima H, Miyoshi N, Tanimoto A and Maruyama I: Coagulation activity and white thrombus formation in the microminipig. In Vivo 27(3): 357-361, 2013. PMID: 23606691.

10 Kawaguchi H, Yamada T, Miura N, Noguchi M, Izumi H, Miyoshi $\mathrm{N}$ and Tanimoto A: Sex differences in serum lipid profile in novel Microminipigs. In Vivo 27(5): 617-622, 2013. PMID: 23988896.

11 Kaneko N, Itoh K, Sugiyama A and Izumi Y: Microminipig, a non-rodent experimental animal optimized for life science 
research: preface. J Pharmacol Sci 115(2): 112-114, 2011. PMID: 21258171. DOI: $10.1254 /$ jphs.10r16fm

12 Murayama N, Kaneko N, Horiuchi K, Ohyama K, Shimizu M, Ito $\mathrm{K}$ and Yamazaki $\mathrm{H}$ : Cytochrome P450-dependent drug oxidation activity of liver microsomes from Microminipigs, a possible new animal model for humans in non-clinical studies. Drug Metab Pharmacokinet 24(4): 404-408, 2009. PMID: 19745566. DOI: $10.2133 / \mathrm{dmpk} .24 .404$

13 Sugiyama A, Nakamura Y, Akie Y, Saito H, Izumi Y, Yamazaki $\mathrm{H}$, Kaneko $\mathrm{N}$ and Itoh $\mathrm{K}$ : Microminipig, a non-rodent experimental animal optimized for life science research: in vivo proarrhythmia models of drug-induced long QT syndrome: development of chronic atrioventricular block model of microminipig. J Pharmacol Sci 115(2): 122-126, 2011. PMID: 21258169. DOI: $10.1254 /$ jphs.10r21fm

14 Yoshikawa T, Takahashi Y, Kawaguchi H, Utsunomiya S, Miura $\mathrm{N}$, Izumi H, Miyoshi N and Tanimoto A: A dermal phototoxicity study following intravenous infusion administration of ciprofloxacin hydrochloride in the novel Microminipigs. Toxicol Pathol 41(1): 109-113, 2013. PMID: 22767873. DOI: $10.1177 / 0192623312452489$

15 Miyoshi N, Horiuchi M, Inokuchi Y, Miyamoto Y, Miura N, Tokunaga S, Fujiki M, Izumi Y, Miyajima H, Nagata R, Misumi $\mathrm{K}$, Takeuchi T, Tanimoto A, Yasuda N, Yoshida $\mathrm{H}$ and Kawaguchi H: Novel Microminipig model of atherosclerosis by high fat and high cholesterol diet, established in Japan. In Vivo 24(5): 671-680, 2010. PMID: 20952732.

16 Takeishi K, Horiuchi M, Kawaguchi H, Deguchi Y, Izumi H, Arimura E, Kuchiiwa S, Tanimoto A and Takeuchi T: Acupuncture improves sleep conditions of minipigs representing diurnal animals through an anatomically similar point to the acupoint (GV20) effective for humans. Evid Based Complement Alternat Med 2012: 472982, 2012. PMID: 22461840. DOI: $10.1155 / 2012 / 472982$

17 Abe M, Kawaguchi H, Miura N, Akioka K, Ushikai M, Oi S, Yukawa A, Yoshikawa T, Izumi H and Horiuchi M: Diurnal variation of melatonin concentration in the cerebrospinal fluid of unanesthetized Microminipig. In Vivo 32(3): 583-590, 2018. PMID: 29695564. DOI: 10.21873/invivo.11279

18 Kawaguchi H, Horie M, Onoue K, Noguchi M, Akioka K, Masatani T, Miura N, Ozawa M and Tanimoto A: Development of a model of porcine epidemic diarrhea in Microminipigs. Vet Pathol 56(5): 711-714, 2019. PMID: 30991905. DOI: $10.1177 / 0300985819839236$.

19 Fontanesi L, Ribani A, Scotti E, Utzeri VJ, Veličković N and Dall'Olio S: Differentiation of meat from European wild boars and domestic pigs using polymorphisms in the $M C 1 R$ and NR6A1 genes. Meat Sci 98(4): 781-784, 2014. PMID: 25134014. DOI: $10.1016 /$ j.meatsci.2014.07.026

20 Ribani A, Utzeri VJ, Geraci C, Tinarelli S, Djan M, Veličković N, Doneva R, Dall'Olio S, Nanni Costa L, Schiavo G, Bovo S, Usai G, Gallo M, Radović Č, Savić R, Karolyi D, Salajpal K, Gvozdanović K, Djurkin-Kušec I, Škrlep M, Čandek-Potokar M, Ovilo C and Fontanesi L: Signatures of de-domestication in autochthonous pig breeds and of domestication in wild boar populations from MC1R and NR6Al allele distribution. Anim Genet 5O(2): 166-171, 2019. PMID: 30741434. DOI: 10.1111/age.12771
21 Rubin CJ, Megens HJ, Martinez Barrio A, Maqbool K, Sayyab S, Schwochow D, Wang C, Carlborg Ö, Jern P, Jørgensen CB, Archibald AL, Fredholm M, Groenen MA and Andersson L: Strong signatures of selection in the domestic pig genome. Proc Natl Acad Sci USA 109(48): 19529-19536, 2012. PMID: 23151514. DOI: $10.1073 /$ pnas.1217149109

22 Burgos C, Latorre P, Altarriba J, Carrodeguas JA, Varona L and López-Buesa P: Allelic frequencies of NR6A1 and VRTN, two genes that affect vertebrae number in diverse pig breeds: A study of the effects of the VRTN insertion on phenotypic traits of a Duroc $\times$ Landrace-Large White cross. Meat Sci 100: 150-155, 2015. PMID: 25460119. DOI: 10.1016/j.meatsci.2014.09.143

23 Yang G, Ren J, Zhang Z and Huang L: Genetic evidence for the introgression of Western NR6Al haplotype into Chinese Licha breed associated with increased vertebral number. Anim Genet 40(2): 247-250, 2009. PMID: 19220230. DOI: 10.1111/j.13652052.2008.01820.x

24 Zhang Y, Wang M, Yuan J, Zhou X, Xu S and Liu B: Association of polymorphisms in NR6A1, PLAG1 and VRTN with the number of vertebrae in Chinese Tongcheng $\times$ Large White crossbred pigs. Anim Genet 49(4): 353-354, 2018. PMID: 29774581. DOI: 10.1111/age.12653

25 Huang J, Zhang M, Ye R, Ma Y and Lei C: Effects of increased vertebral number on carcass weight in PIC pigs. Anim Sci J 88(12): 2057-2062, 2017. PMID: 28776879. DOI: 10.1111/asj.12881

26 Mikawa S, Sato S, Nii M, Morozumi T, Yoshioka G, Imaeda N, Yamaguchi T, Hayashi T and Awata T: Identification of a second gene associated with variation in vertebral number in domestic pigs. BMC Genet 12: 5, 2011. PMID: 21232157. DOI: 10.1186/1471-2156-12-5

27 Kaltenbrunner M, Mayer W, Kerkhoff K, Epp R, Rüggeberg H, Hochegger R and Cichna-Markl M: Differentiation between wild boar and domestic pig in food by targeting two gene loci by realtime PCR. Sci Rep 9(1): 9221, 2019. PMID: 31239519. DOI: 10.1038/s41598-019-45564-7

28 Lorenzini R, Fanelli R., Tancredi F, Siclari A and Garofalo L: Matching STR and SNP genotyping to discriminate between wild boar, domestic pigs and their recent hybrids for forensic purposes. Sci Rep 10(1): 3188, 2020. PMID: 32081854. DOI: 10.1038/s41598-020-59644-6

29 Klomtong P, Chaweewan K, Phasuk Y and Duangjinda M: $M C 1 R, K I T, I G F 2$, and NR6A1 as markers for genetic differentiation in Thai native, wild boars, and Duroc and Chinese Meishan pigs. Genet Mol Res 14(4): 12723-12732, 2015. PMID: 26505423. DOI: $10.4238 / 2015$.October. 19.16
Received October 13, 2020

Revised November 3, 2020

Accepted November 6, 2020 